
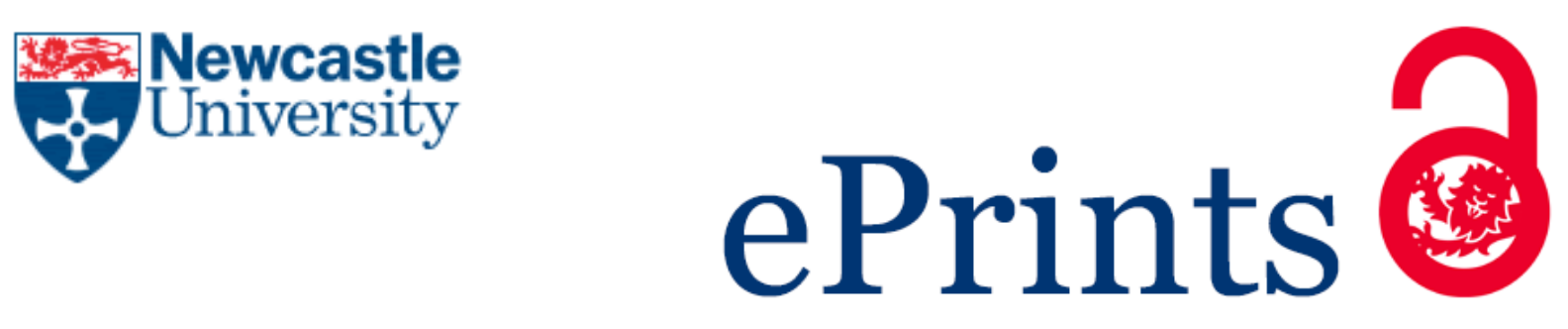

Chappell L, Mawdsley J, Petrov P.

Strategy in European Security and Defence policy: does it matter?.

In: Chappell, L; Mawdsley, J; Petrov, P, ed. The EU, Strategy and Security

Policy: Regional and Strategic Challenges.

London: Routledge, 2016, pp.1-16.

\title{
Copyright:
}

This is an Accepted Manuscript of a book chapter published by Routledge in The EU, Strategy and Security Policy: Regional and Strategic Challenges on 25/5/2016, available online:

http://www.routledge.com/The-EU-Strategy-and-Security-Policy-Regional-and-Strategic-

Challenges/Chappell-Mawdsley-Petrov/p/book/9781138899483

Date deposited:

$25 / 05 / 2016$

Embargo release date:

25 November 2017

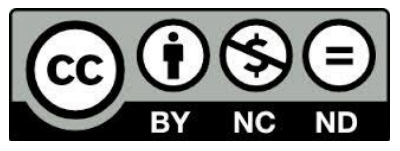

This work is licensed under a

Creative Commons Attribution-NonCommercial-NoDerivatives 4.0 International licence 


\section{Strategy in European Security and Defence policy - does it}

matter?

Laura Chappell, Jocelyn Mawdsley and Petar Petrov

Engelbrekt (2008) argued that there was a strange paradox between the European Union's (EU) ability to produce policies that possess certain strategic qualities, and its lack of the institutions and concepts that would enable it to reason strategically. This shortcoming has been most marked in the field of security. In the intervening years the EU has developed the institutional structures of its Common Security and Defence Policy (CSDP) but CSDP still lacks overt strategic purpose (Kempin and Mawdsley, 2013). The EU has failed to find consensus on what and where the CSDP should be active, leading to embarrassing inaction at a time of multiple security crises in the EU's neighbourhood. In the cases of Libya and Mali, this inaction has led some member states to use alternatives such as the North Atlantic Treaty Organisation (NATO) and unilateral national action. There is no doubt that the CSDP lacks military capacity. It is therefore unsurprising that calls have been made repeatedly to strengthen the CSDP by increasing "pooling and sharing" (P\&S), by reviving Permanent Structured Cooperation in Defence, creating a single market for armaments projects and linking EU-wide level military equipment goals to European defence industrial policies (Kempin 2013; Darnis 2013; Future of Europe Group, 2012). But while important, such measures do not really tackle the core question of what the member states want the EU to achieve as a military actor.

The special European Council summit in December 2013 drew Member State attention to defence, and the CSDP has gathered some new momentum for the first time in some years. The summit did make progress, formalising EU actions on long-discussed issues such as 
capability development, cyber/maritime security and strengthening Europe's defence industry and to leave no doubt about the seriousness of the matter, explicitly declared: "Defence matters" (European Council, 19/20 Nov. 2013, part I, par.1). However it also demonstrated that the policy lacks a clear sense of purpose. The piecemeal nature of the summit conclusions revealed a long-observed absence of an over-arching strategy, strengthening the impression that the CSDP is, if not in crisis, at best in a state of stasis.

However the European Council was correct in its assessment that defence matters. The EU is facing a number of contemporary security challenges such as the slow and uncertain recovery from the financial crisis, consistent declines in national defence spending, tensions with Russia over the conflicts in Ukraine and Syria, heightened perceptions of energy vulnerability, and turmoil in the Middle East and North Africa, including the Sahel region. Moreover, even beyond its immediate neighbourhood, the EU needs to be able to respond to security situations that will have an impact on its trading patterns. For example, the rising tensions between China and its neighbours over sovereignty in the South China Sea have the potential to destabilise some of the EU's most important trading partners. There are new areas of vulnerability emerging for the EU and its member states such as cybersecurity, the need to keep trading routes protected from piracy and the external dimensions of the EU's internal security challenges. All of this comes at a time where other global actors are expecting more from the EU and its member states, be that in terms of the United Nations (UN) 'responsibility to protect' doctrine or the United States' pivot towards the Pacific.

Increasingly, even the strongest military powers in the EU, Britain and France, accept that they cannot deal with global security problems on their own, but despite the strength of the argument for collective action, the EU has been unable to act. This has given rise to 
widespread cynicism about the EU's ability to develop a truly common security and defence policy. Fifteen years since the establishment of the CSDP, the EU is still unable to forge a common strategic vision that goes beyond the general framework of principles established by the European Security Strategy in 2003. In light of these challenges, for some observers the only way in which the EU can make a qualitative difference and demonstrate a clear break with the past is by forging a stronger commitment to the development of a "common strategic outlook" (de France and Whitney 2013). Similarly, others have called for the development of a grand strategy (Biscop and Coelmont, 2010).

Such calls seem all the more pressing given that the security challenges in the next couple of decades will revolve around scarcity of resources (energy, food and water), unemployment (especially in youth-rich countries which are part of the 'arc of instability'), poverty, state failure and immigration (National Intelligence Council, 2008 iv-v; National Intelligence Council, 2012 ii). In this sense, the root-causes of insecurity are increasingly related to the ways in which the individual is affected by these challenges and able to cope with them in a sustainable manner within society. If the EU is to live up to its potential as a comprehensive security actor, then it will need to draw on a range of strategic instruments to respond successfully. In the domain of security and defence this means the skilful application of both civil and military conflict prevention and management instruments to (potential) crises. It may seem as though the development of a grand strategy is vital for the EU to reach its potential as an international actor. The question is whether there is sufficient consensus amongst the member states to agree a document with more strategic bite than the European Security Strategy. While the experience of the French EU presidency in 2008, which attempted to get such a process underway and largely failed, was discouraging (Irondelle and Mérand, 2010), the EU is once again venturing down this track, with the High, 
Representative, Federica Mogherini, being tasked in June 2015 by the European Council with developing a Global Strategy by June 2016. However some argue that once again the security dimension of the EU's international actorness is being neglected in the process set out by Mogherini (Major and Mölling, 2015; Kaca, 2015).

This book does not attempt to develop a grand strategy, rather it asks to what extent the EU is able to use its security policy capabilities in a strategic fashion. The main research question of the book is to what extent is the EU acquiring any form of overarching strategic framework? It is also timely as it allows for an interrogation of whether (or not) the EU has the strategic concepts and institutions in place, that Engelbrekt (2008) thought necessary for the EU to become a strategic actor. Throughout the book the EU's claims that it is committed to effective multilateralism and a comprehensive approach to security are examined through different case studies. The Treaty of Lisbon was supposed to bring a new coherence to external action, and so the book also looks at the extent to which the new institutions are producing more coherent external action.

Despite all of the negativity surrounding the CSDP, the EU is being forced to act on security matters. The aim of this book is to take stock of what the EU is doing in geographical areas that it considers important, on security threats that it has defined as vital and what practical progress it is making on some of the known barriers to strategic coherence. In short, it aims to explore the EU's strategic actorness. This will help us define what sort of a security actor the EU is currently and where there are signs of strategic coherence emerging from bottom-up policy actions. This introduction will give a brief overview of the concept of strategy and how it might be understood with respect to the EU. It will then look at the ways in which the EU might be considered to have strategic purpose and then ask how it might operationalise it. 
Finally, it will introduce the structure of the book and its research questions.

\section{Strategy and the EU}

Strategy is a concept that has become ubiquitous across multiple fields of twenty first century life, but as Freedman (2013: x) remarks, it is still the best word to capture the essence of our 'attempts to think about actions in advance, in the light of our goals and capacities'. This book interests itself in the subject of strategy in its classic sense, namely as Liddell Hart (1967: 231) puts it: 'the art of distributing and applying military means to fulfil the ends of policy'. While strategic studies as an intellectual discipline emerged during the early years of the Cold War, strategy as a concept has much earlier origins, with perhaps the most influential being writings from ancient Greece (Freedman, 2013). The work of Athenian historian and general, Thucydides, in particular, remains on the syllabi of many military colleges to this day. His account of the Peloponnesian War is thought to offer the first complete theory of grand strategy (Platias and Koliopoulos, 2010). Sun Tzu's The Art of War and Clausewitz's On War also remain influential.

Nevertheless how we think about military strategy today is heavily influenced by the discipline of strategic studies, and it is worth considering where their emphases lie, before we move to relating it to the EU. While many early definitions of strategy relate uniquely to war, more recent strategic studies scholars have broadened this approach. For example, Osgood (1962) agrees with the likes of Thucydides that power is a crucial determinant in any conflict, but argues that the state's capacity for military coercion should be exercised conjointly with economic, political and psychological sources of power in an overall strategy. Strategic studies' Cold War origins and the centrality of nuclear deterrence as a strategic concept meant that for its students, strategy mattered in peacetime as well as during war. Authors like Liddell Hart (1967) developed the concept of grand strategy to mean the devotion of all a 
nation's resources towards the achievement of national political goals. In other words, strategists will use military means to achieve national goals but this will be within the wider context of national resources. The state-centrism of strategic studies makes the application of their concepts of strategy hard to apply to the EU as it lacks automatic recourse to these type of state-based resources. Nonetheless Engelbrekt (2008) argues that by drawing on the wider understanding of strategy (as understood by Liddell Hart) the EU can potentially be understood as a type of strategic actor, which could draw on some military means alongside other instruments of power.

What though is meant by a strategic actor? Hallenberg (2008: 3) argues that classically a strategic actor should have five characteristics:

1) Possess an independent capacity to gather and evaluate intelligence,

2) Be able to formulate political goals and have a hierarchy among these goals,

3) Be able to select wisely among the resources at its disposal to achieve these goals,

4) Possess the ability to practically implement its strategy on the ground,

5) Be able to evaluate its own actions and learn for the future.

However as Engelbrekt (2008) points out, despite the EU's obvious economic power and political attraction, which allow it to influence global politics, its CSDP activities lack the clear strategic rationale that usually inform the preparation for and conduct of military action in a militarily active nation state. CSDP remains heavily dependent on the good will of certain key member states, and its institutions, while they have increased the EU's capacities, remain weak. Although the EU may have some level of capacity to act strategically, its abilities to anticipate, evaluate and respond to another more cohesive actor are basic at best, as the crisis in Ukraine has showed. Moreover, the military resources of many of the member states are lacking. In short, on traditional measures of strategic actorness, as Engelbrekt argues the EU cannot currently be regarded as an autonomous strategic actor. Therefore it can 
be argued that the EU is doomed to remain, in Wagnsson's (2008) terms, a passive pole (an economic giant but a passive subordinate to the US in security matters) or at best a pragmatic re-actor (able to react to predictable situations where consensus exists) rather than a strategic actor in the field of security and defence policy.

Do the military weaknesses of the EU preclude the development of the CSDP into a strategic policy tool of the EU though? Howard (1979) cautioned against reducing the concept of strategy to a measure of the quality of an actor's armaments. Engelbrekt (2008) for example suggests that turning to the more holistic understanding of strategic actorness offered by Colin Gray may help us develop a more realistic understanding of the sort of strategic actor the EU might become. Gray (1999a: 24) argues that there are seventeen dimensions of strategy clustered into three categories: people and politics (people, society, culture, politics and ethics); preparation for war (economics and logistics; organisation [e.g. defence planning]; military administration [e.g. recruitment]; information and intelligence; strategic theory and doctrine and technology) and war proper (military operations; command; geography; friction; the adversary and time). Engelbrekt (2008) argues that in many ways the EU is well-suited to manage the parameters of the first category and that its work towards increasing efficiency and decreasing duplication may help it strengthen the overall military capabilities of its member states in the second category, even if the likelihood of the EU engaging in war proper remains remote. Similarly, Wedin (2008) draws on the French general Poirier's understanding of the different levels of strategy to argue that even if the EU is far from developing a hierarchised set of political objectives to constitute the aims of a grand strategy, it is gradually acquiring the 'ways and means' at an operational level, which may enable the bottom-up rather than top-down development of strategy. Indeed Biscop and Norheim-Martinsen (2011: 80) underscore that 'acting European has become a source of 
strategic identity for the EU and an end in itself', rather than the EU's actorness being based on a series of strategic objectives. It is these more limited ambitions for the EU as a strategic actor, and the potential of Wedin's (2008) proposal that the EU may be able to develop bottom-up strategy based on operational experience that inform the structure of this book.

It is undeniable that referring to the EU as a strategic actor at all, raises the question of whether we are reifying, that is transforming the abstract to concrete, the EU as a security power. Is the EU as a security actor no more than a cluster of institutions and procedures, and thus what collective security actions emerge, are simply the combined actions of the principal member states? While we accept that the member states remain crucial to the success or otherwise of CSDP policy actions (see the chapter by Chappell, Mawdsley and Whitman in this volume), we would argue that there is a dimension to CSDP that goes beyond this. In a similar discussion on foreign policy, Smith (2011) rightly points out that compared with thirty years ago, it is evident that we can see more cooperation, integration and foreign policy action; this can also be observed in the security domain. CSDP is not, as understood by this book, a policy area that can be separated out from other EU security actions (see the chapters by Barrinha and Carrapiço and Shepherd). Moreover, the institutionalisation process itself can be thought of as constitutive.

Holland (2002) suggested that for every external policy action, the EU goes through an internal process of identification and legitimatisation and an external process of justification and projection. Birchfield (2013) takes this argument a stage further in arguing that the EU is an innately reflexive actor. Arguably, this process would be expected to be at its most extreme when the EU deals with security-related matters, and certainly more recently where military operations are concerned, this is the case. In some ways however, this book 
challenges these assumptions in questioning the extent to which the EU is reflecting on its security actions and thus behaving as a strategic actor. However, we would argue that if not currently a reflexive security actor, the EU has the potential and aspirations to be one, and thus that it is legitimate to treat it as an emerging security actor.

\section{The EU's strategic purpose}

If we accept the EU can be considered an emerging security actor, the next step is to ask what its strategic purpose is. Whilst strategy is about matching means with outcomes as outlined above, it is necessary to take a step back and ask: means and outcomes for what core purpose? The issue here lies with the military power connotations of strategy which hardly fit an actor such as the EU, which professes to hold a 'comprehensive approach' to security to include a multitude of different instruments up to and including the use of force (European Council 2003). As Biscop and Norheim-Martinsen (2011: 65) emphasise, 'the essence of strategy ultimately boils down to the extent to which any instruments of power -military as well as non-military - further a perceived political end'. Whilst the EU might be lacking a 'grand' strategy there are still elements of strategic thinking as evidenced in the 2003 European Security Strategy (ESS). Two key concepts here are a comprehensive approach to security as mentioned above and effective multilateralism, involving working with partners in the context of international law. Although these could be considered to be an EU 'way of conducting war', what the ESS misses out is a comprehensive outline of what the EU's values and interests are (see Biscop and Norheim Martinsen 2011: 70; 79). Whilst a Member State such as Germany found certain elements of the ESS to be challenging, for example the possibility of taking preventive action (Chappell, 2012), at the same time the ESS was largely uncontroversial, mainly because in contrast to the US National Security Strategy it identified threats but did not specify a set of strategic responses. 
For Solana, the key to making the ESS exist in reality rather than just on paper was the development of a common EU strategic culture, which would 'improve decision-making, facilitating rapid and, if necessary, robust intervention in crisis situations' (Mawdsley and Quille, 2003: 12). It is unsurprising that much of the academic literature, which has delved into whether the EU's actions amount to anything more than the EU Member States' eclectic national interests, uses strategic culture. Taking Gray's (1999b) notion of culture as context, a strategic culture approach seeks to understand the actions of a security community relating to crisis management through inter alia a focus on historical experience, cultural beliefs and norms as well as the capabilities required to implement its vision of security (Gray 1999b, Meyer 2006, Longhurst 2004). Thus connections are made between beliefs, attitudes and norms held within a security community, how these are articulated in policy documentation and subsequently actioned in the security environment (Chappell and Petrov 2014).

Whether the EU has any form of strategic culture is contested. Critics such as Rynning (2003) and Heiselberg (2003) point to divergences between the Member States concerning the use of force. Meanwhile proponents underscore that the beginnings of a European strategic culture are emerging. This is either through convergence between Member States concerning when, where and how the EU uses force (Meyer 2006; Chappell 2012) or alternatively examining primarily military operations and CSDP developments at the EU level (Cornish and Edwards 2005; Chappell and Petrov 2014). The added value to the strategy debate is to underscore that strategy has to have a purpose attached to it, whether this is based on rational, cultural, normative and/or historical factors. In other words strategic action always has a context in which it is enacted. This can be developed either as a top down process (developing beliefs and norms regarding crisis management which informs instruments and outcomes) or a 
bottom up process related to developing capabilities and policy learning which come to inform interests and norms regarding subsequent action.

The ESS gave a basic guideline as to how the EU views security rather than some form of grand strategy as its title might suggest. From the ESS and the subsequent 2008 Report on the Implementation of the ESS, a number of "sub-strategies" have been created which can be separated into two categories. The first encompasses regional areas and includes for example the 2011 Strategy for Security and Development in the Sahel (see Kempin and Scheler in this volume), the 2007 Africa-EU strategy and the 2011 Strategic Framework for the Horn of Africa. The second relates to identified challenges and comprises inter alia the 2003 EU Strategy against Proliferation of Weapons of Mass Destruction, the 2013 Cybersecurity Strategy of the European Union (see Barrinha and Carrapiço in this volume), the 2010 Internal Security Strategy (see Shepherd in this volume) and more recently the 2014 EU Maritime Security Strategy (see Smith in this volume). These documents can be seen to be 'activating' some elements of strategy contained within the ESS. However the question remains as to how 'strategic' they really are not only within each one but also whether they add up to a coherent EU approach to security.

Within the sub-areas, it is easier for the EU to outline its strategic challenges, priorities and the tools required to combat these, as the Cybersecurity Strategy for example shows (European Commission 2013). This is because the threat has clearly been identified (in the 2008 Report) and there are specific instruments and policies which have already been put in place or are being developed, although significant barriers remain (see Barrinha and Carrapiço in this volume). In the case of the Maritime Security Strategy it declares 'sea matters' and states the EU and its Member States have 'strategic interests, across the global 
maritime domain' (Council of the European Union 2014: 2). Whilst it mirrors the ESS in regards to some of the principles it uses (e.g. multilateralism and a comprehensive approach), it is more exact in specifying objectives and how these are to be met. There is also some evidence that different sub-strategies are cross-referenced (e.g. the EU-Africa Strategy, the EU Counter-Terrorism Strategy and the Internal Security Strategy are referred to in the Strategy for Security and Development in the Sahel). Whilst those sub-strategies related to threats identified in the ESS and the 2008 Report are clearly important, it is not evident within those dealing with regions as to where they lie in the EU's strategic priority list. Having a regional strategy does not automatically lead to Union positions or decisions to take action on the ground, through the deployment of a CSDP military operation or civilian mission for example.

This book sets out to ask what approach to security the EU takes to various regions and issue areas and why, what outcomes the EU wants and which capabilities it has been utilising to this end. Hence it seeks to ascertain whether there is more to European strategy than the ESS and the 2008 Report set out. In this respect, this book will examine inter alia the various substrategies and set out whether there is a strategic vision across policy areas and geographical spaces or whether significant variations occur. Thus rather than asking whether or not the EU has a strategy instead we are focusing on how effective the EU is as a strategic actor. It is perfectly feasible for the EU to have a full or partial strategy in some areas and not in others. In this respect we are looking at strategy as a process rather than a static definition based on the absence or presence of one (Biscop and Norheim Martinsen 2011: 68). Therefore what this adds up to in terms of the EU as a strategic actor is likely to be a mixed picture.

\section{Operationalising a strategic approach: a framework for analysis}


Considering that an EU strategy is intended to match means with outcomes which are in the best interests of the EU (whether based on rational or normative premises) it is necessary to consider what type of instruments we need to examine and how are we able to ascertain their strategic usefulness. As outlined in our discussion on the EU and strategy above, we take as a starting point the EU's comprehensive approach to security. Therefore our approach is based on both civilian and military aspects of CSDP and reflects key threat perceptions as identified in the ESS as well as the Report on the Implementation of the ESS.

To underline what these instruments contribute towards the evolution of the EU as a strategic actor we take four areas. The first area relates to strategic priorities and objectives (Biscop and Coelmont 2011: 4) which give the basic security rationale for undertaking action. This includes the notion of threat perception i.e. the types of threats and geographical areas related to them. Here we are concentrating on the EU's approach and interests towards different geographical areas or challenges as identified in the ESS and the subsequent 2008 report. In this respect, we evaluate why the EU has decided to focus on certain strategic challenges.

Once this has been established the next step relates to how the EU decides to combat the identified threats. These can be both civilian and military in nature. We concentrate on what CSDP adds to already existing 'softer' instruments in the field and how the EU approaches strategy. This is combined with the third area relating to other external actors and includes whom the EU wants to work in concert with as well as strategies the EU wants to pursue against other actors considered a threat (Haine 2011: 585). This links in with the EU's ‘effective multilateralism'. Finally, in order to carry out a strategy, the necessary institutional and capability resources are required and should form a coherent set of instruments. 
When assessing the EU as a strategic actor we are therefore focusing on the extent to which means and ends are in synergy with each other. To summarise, we need to ascertain whether EU action on the ground reflects a strategic approach in relation to:

1. identifiable EU priorities, seen through EU policies, documentation and speeches by decision-makers,

2. how the EU is combating these elements of (in)security, (this includes the types of operations and/or tasks which the EU considers optimal to meet its priorities as well as whom it works with as emphasised by the EU's supposed 'effective multilateralism'.),

3. the military/civilian capabilities it is using.

In line with the bottom up approach to security we could equally see tools being created and used which are reflected in the way in which the EU approaches and conducts security. However, to avoid the impression that the EU is on a continual forward trajectory, we also concentrate on not only strategic opportunities but also barriers to the EU's 'development' as a strategic actor. These include military capabilities, differing approaches of the EU's Member States as well as the EU-NATO relationship. Thus the key aim of this edited collection is to assess the state of play in the EU's development as a strategic actor, where barriers occur and why and then to suggest ways forward.

\section{Structure of the Book}

The book offers a contemporary assessment of the challenges and possibilities for reviving the CSDP. Taking a critical view, we aim to map the EU's strategic vision(s) across key regions, identified strategic priorities and cross-cutting challenges to assess the extent to which these add up to anything more than a series of disjointed actions. By doing this we demonstrate where gaps in strategic thinking lie, where the EU has been unable to achieve its 
aims, and offer recommendations concerning the EU's future strategic direction. The contributions to this edited collection are arranged into three sections, each covering a distinctive challenge to the emergence of a coherent EU strategy on security. Each section is structured around a set group of questions to provide a focus which in turn connects to the main aim of the book: to explore the EU's strategic actorness.

\section{Regional Challenges}

Part one focuses on the regional challenges to the development of a coherent European security strategy with chapters concentrating respectively on: the Eastern Neighbourhood (Juncos); the Sahel and the Horn of Africa (Kempin and Scheler), the Middle East and North Africa (Mühlberger and Müller) and Asia (including the Pacific and ASEAN) (Merrett). Within this section, the authors have been asked to respond to the following questions:

1. Is there a (developing) strategy in relation to the region? What are the EU's interests?

2. What does/can CSDP add to existing EU policy instruments?

3. To what extent does the EU cooperate with other key actors/regional organisations?

Therefore this section will map out the EU's strategic actorness in different geographical areas to ascertain whether the EU has some form of global or regional approach to security. The different case studies help to show where security fits (or does not) in the EU's policies towards different regions.

The EU has clear security interests in both the Balkans and the Eastern neighbourhood and the stabilisation of both regions is a challenge that the EU needs to meet. In her chapter Juncos begins by outlining what is at stake, then moves to questioning whether CSDP actions and resources are better integrated into overall EU policy when the EU has a clear end goal enlargement in the case of the Balkans - compared to the Eastern neighbourhood where the 
end goal of the engagement is far from clear. Additionally, Juncos looks at whether security policies are a beneficial addition to the EU toolkit, in two regions where its influence is contested by Russia.

The Sahel and the Horn of Africa are regions with a complex mix of problems, but whose instability is increasingly understood as a threat to the EU's own security. Both areas are subjects of recent, carefully developed EU regional strategy documents, both of which stress the need for effective multilateralism and a comprehensive approach towards security. In their chapter Kempin and Scheler examine to what extent these strategic concepts exist beyond these documents, by comparing the implementation record of these regional strategies. They ask whether the CSDP actions in the regions are being effectively combined with other EU policy tools and if this is being done in partnership with other regional actors.

Mühlberger and Müller tackle the EU's difficulties in responding to the Arab Spring in the Middle East and North Africa with a particular focus on the struggles in developing a coherent response to the conflict in Libya. Again they question the extent to which claims of a comprehensive approach, where security policy tools are part of a holistic approach, hold up, particularly in a region where the EU's own security needs (migration, counter-terrorism and energy security) have been prioritised over good governance in the past. In this chapter, the authors also tackle the problem of an internal lack of strategic consensus on how to respond to an emerging conflict.

Finally in this section Merrett, moving away from a focus on the EU's immediate neighbourhood, asks what role security policy should play in a region crucial to the EU's future economic interests, Asia. Merrett points out that the EU's interests depend heavily on 
regional stability in Asia meaning that it needs to be concerned about three potential security flashpoints. Using a case study of the CSDP Aceh Monitoring Mission, he makes the case that the EU can be a constructive security actor in the region. Merrett questions whether fears of a strategic over-reach really outweigh the potential usefulness of the EU as a regional security actor.

\section{Strategic Challenges}

Part two concentrates on a number of topical strategic challenges to the evolution of a coherent European security strategy, which have been agreed as strategic priorities by the EU. Among these are the internal-external security nexus and CSDP (Shepherd); the EU's security actorness in cyber space (Barrinha and Carrapiço); the development of a maritime security capability within the CSDP (Smith) and the EU-UN partnership in light of R2P (Schmidt). The key questions which inform this section include:

1. Why has the EU decided to be an actor in this field? Is there an identifiable EU interest?

2. To what extent is the challenge informed by a strategic approach?

3. How effective has the EU been in this field?

The emphasis here is placed on the intertwining of civilian and military aspects to understand the EU's comprehensive approach to security, thus underlining what could be its unique role in the international security environment.

Shepherd's chapter which focuses on the internal-external security nexus, underscores the emerging security continuum. It is here where the EU is trying to position itself as a unique security actor able to add value through the comprehensive approach which intertwines internal and security capabilities. However despite the changing nature of security threats 
which underscores the importance of utilizing internal and external instruments particularly operationally, CSDP is hampered by institutional stove-piping. In this respect friction and turf wars remain, undermining the EU's ability to be a strategic internal-external security actor. Hence Shepherd calls for adjustments to the EU's institutions and capability profile to meet today's transboundary challenges.

Likewise Barrinha and Carrapico highlight the high political salience of cyber security which encompasses network and information security, law enforcement and defence. In particular the EU is in a favourable position to become one of the key institutional actors in this area as it has the institutional set up and strategic background. Indeed it could be deemed to be a normative cyber power. However the area of cyber security suffers from a 'proclamationimplementation' gap which highlights the difference between the EU's discursive framing and its practices/institutional layout. In this respect obstacles remain regarding the EU's abilities in this area.

Smith's chapter connects with Shepherd's in respect to placing the comprehensive approach at the heart of the EU's approach. In the maritime dimension, this concept underscores the confluence of CSPD capability-building, the development of the Integrated Maritime Policy and the launch of ATALANTA. The latter in particular combines key EU interests encompassing humanitarian, development and human rights dimensions. Smith notes that the EU's CSDP actions in the Horn of Africa were path-breaking as they respond not just to EU but also regional and international security threats. Whilst they could have been more thorough in respect to planning, nonetheless this area demonstrates that the EU can act comprehensively. 
Finally, Schmidt underscores that despite the EU's commitment to R2P, in reality EU engagement in recent humanitarian crises falls short of the organisation's potential to be a military security provider and partner of the UN as highlighted by the importance of its 'effective multilateralism'. The EU's emphasis is on long term preventative initiatives which reflects its preference for crisis management. Indeed there is no strong agreement between the Member States regarding when collective responsibility should apply. This underlines the lack of a strategic approach and a reluctance to act decisively particularly in regards to the use of military force in the framework of R2P.

\section{Strategic Opportunities and Barriers}

The final section highlights specific strategic opportunities and barriers. In particular the three chapters encompass: the complementarities and differences between the strategic outlooks of the EU and NATO (Duke and Vanhoonacker); national priorities (France, Germany and the United Kingdom) and EU strategy (Chappell; Mawdsley and Whitman); military capabilities and force transformation (Galbreath and Smith). The leading questions in this part are:

1. How does the EU address strategy in these areas?

2. To what extent has the EU been able to overcome barriers to strategic thinking in this area?

3. To what extent do competing strategies from the different actors enable/constrain strategic developments?

4. What are other impeding factors to a more cohesive strategy?

Our aim here is to understand where the limits to the EU as a strategic actor lie and how they can be overcome, if at all. 
Duke and Vanhoonacker show that although for both the EU and NATO 'strategy' has not been irrelevant they have often been stuck with broad statements of intent rather than a coherent plan of action. The legacy of the cold war whereby both organisations developed largely parallel, and occasionally overlapping tracks, is still having an impact today. Lacking well-articulated security strategies and in the absence of a strongly institutionalized interaction at the political level, they are locked into strategic paralysis. Cooperation in the Gulf of Aden, Afghanistan and Kosovo has been informal and ad hoc in nature and it is unclear whether this can lead to future strategic convergence.

In analysing any specific CSDP logic to defence reform, as observed through the EU's role in capability development and force transformation, Galbreath and Smith ask whether there are competing logics to capabilities and transformation that affect all EU states who are also NATO alliance members. In particular they contend that capabilities and transformation remain nationally determined and externally shaped by past and current operations so the EU is less influential in setting out a strategy in these areas. The main barriers to strategic thinking seem to be related to national sovereignty, constitutional neutrality, commitments to NATO and trust.

Chappell, Mawdsley and Whitman address the question of whether the EU's role as a security actor is dependent on the participation of the largest three states, France, Germany and the UK. They start by questioning the extent to which the strategic purposes and priorities of the three states are in line with each other and how they envisage the EU developing as a security actor. The chapter then looks at the extent to which the policy actions of the three states are enabling or constraining the strategic development of the CSDP. 
The conclusion of the book brings together the different strategic visions discussed in the respective chapters and looks into whether the CSDP represents more than a collection of distinctive actions and/or ad hoc mini-strategies. Moreover, synergies between strategies as well as areas of strategic inconsistency will be uncovered to give a picture of where the EU is headed as a strategic actor. Finally we make recommendations for a future EU security strategy in which all the observed pieces of strategic thinking in the EU can be brought together contributing to the formation of a coherent EU strategy on security.

\section{References}

Birchfield, Vicki (2013) A normative power Europe framework of transnational policy formation, Journal of European Public Policy, 20(6), 907-922

Biscop, Sven and Norheim-Martinsen, Per. (2011) 'CSDP: The Strategic Perspective'. In Kurowska, Xymena and Breuer, Fabian (eds). Explaining the EU's Common Security and Defence Policy: Theory in Action. Basingstoke: Palgrave Macmillan, 63-85.

Biscop, Sven and Coelmont, Jo (2010) 'A Strategy for CSDP. Europe's Ambitions as a Global Security Provider', Egmont Paper 37. Available at: http://www.egmontinstitute.be/wp-content/uploads/2013/09/ep37.pdf

Chappell, Laura. (2012) Germany, Poland and the Common Security and Defence Policy. Converging Perspectives in an Enlarged EU. Basingstoke: Palgrave Macmillan 
Chappell, Laura and Petrov, Petar (2014) 'The European Union's crisis management operations: Strategic culture in action?', European Integration online Papers (EIoP), Vol. 18, Article 2, http://eiop.or.at/eiop/texte/2014-002a.htm,1-24.

Cornish, Paul and Edwards, Geoffrey. (2005) 'The Strategic Culture of the European Union: a Progress Report'. International Affairs, 81(4), 801-820.

Council of the European Union (2014) European Union Maritime Security Strategy, 11205/14. Available at:

http://register.consilium.europa.eu/doc/srv?l=EN\&f=ST\%2011205\%202014\%20INIT

Darnis, Jean-Pierre (2013) The European defence industry's future: how European?, in Think Global, Act European IV: Thinking Strategically about EU's External Action. Available at: http://www.notre-europe.eu/media/tgae2013.pdf?pdf=ok,, 284-292

de France, Olivier and Nick Witney, (2013) Europe's Strategic Cacophony, Policy Brief, ECFR/77, April 2013.

Engelbrekt, Kjell (2008) Machiavelli and the Making of a European Security and Defence Strategy, in Kjell Engelbrekt and Jan Hallenberg (Eds.), The European Union and Strategy: An Emerging Actor, London, Routledge, 9-21

European Commission (2013) Cybersecurity Strategy of the European Union: An Open, Safe and Secure Cyberspace, JOIN (2013) 1 final. Available at: http://ec.europa.eu/digital- 
agenda/en/news/eu-cybersecurity-plan-protect-open-internet-and-online-freedom-and-

opportunity-cyber-security

European Council, (2003) A Secure Europe in a Better World - European Security Strategy.

Brussels: Council of the European Union.

Future of Europe Group (2012) Final Report of the Future of Europe Group (FEG), of the Foreign ministers of Austria, Belgium, Denmark, France, Italy, Germany, Luxemburg, the Netherlands, Poland and Spain, 17 September 2012.

Freedman, Lawrence (2013) Strategy: A History, Oxford: OUP

Gray, Colin (1999a) Modern Strategy, Oxford: OUP

Gray, Colin (1999b) 'Strategic Culture as Context: The First Generation of Theory Strikes Back’. International Affairs, 7(1), 49-69.

Haine, Jean Yves (2011) 'The Failure of a European Strategic Culture - EUFOR CHAD: The Last of its Kind?', Contemporary Security Policy, 32(3), 582-603.

Hallenberg, Jan (2008) 'Introduction', in Kjell Engelbrekt and Jan Hallenberg (Eds.), The European Union and Strategy: An Emerging Actor, London, Routledge: 1-6 
Heiselberg, Stine. (2003) Pacifism or Activism: Towards a Common Strategic Culture Within the European Security and Defense Policy?. ISS Working Paper, no. 2, Copenhagen: Danish Institute for International Studies, 1-36.

Holland, Martin (2002) The European Union and the Third World, New York: Palgrave.

Howard, Michael (1979) The Forgotten Dimensions of Strategy, Foreign Affairs, 57(Summer), 976-86

Irondelle, Bastien and Frédéric Mérand (2010) 'France's return to NATO: the death knell for ESDP?' European Security, 19(1), 29-43

Kaca, Elżbieta (2015) The Labours of HR Federica Mogherini: Her Pursuit of a Strategy and Effectiveness, The Polish Institute of International Affairs Strategic File, No. 14(77), July 2015, Warsaw

Kempin, Ronja (2013) How to maintain hard capabilities in times of budget cuts?, in Think Global, Act European IV: Thinking Strategically about EU's External Action. Available at: http://www.notre-europe.eu/media/tgae2013.pdf?pdf=ok, 276-283

Kempin, Ronja and Jocelyn Mawdsley (2013) The Common Security and Defence Policy as an Act of American Hegemony, European Security, 22(1), 55-73

Liddell Hart, Basil (1967) Strategy, London: Faber (2 ${ }^{\text {nd }}$ edition) 
Longhurst, Kerry (2004) Germany and the Use of Force. Manchester: Manchester University Press.

Major, Claudia and Christian Mölling (2015) The Place of Security in the EU's new Global Strategy, European Leadership Network. Available at: http://www.europeanleadershipnetwork.org/the-place-of-security-in-the-eus-new-globalstrategy_2970.html

Mawdsley, Jocelyn and Gerrard Quille (2003) Equipping the Rapid Reaction Force - Options for and Constraints on a European Defence Equipment Strategy, BICC Paper 33 (August 2003), Bonn International Center for Conversion, Bonn and ISIS-Europe, Brussels

Meyer, Christoph, (2006) The Quest for a European Strategic Culture: Changing Norms on Security and Defence in the European Union. New York: Palgrave Macmillan.

National Intelligence Council (2008) Global Trends 2025: A Transformed World, National Intelligence Council (NIC). Available at: http://www.dni.gov/files/documents/Newsroom/Reports\%20and\%20Pubs/2025_Global_Tren ds_Final_Report.pdf

National Intelligence Council (2012) Global Trends 2030: Alternative Worlds, National Intelligence Council (NIC), Available at: 
Osgood, Robert (1962) NATO: The Entangling Alliance, Chicago: University of Chicago Press

Platias, Athanassios and Constantinos Koliopoulos (2010) Thucydides on Strategy: Grand Strategies in the Peloponnesian War and Their Relevance Today, New York: Columbia University Press

Rynning, Sten. (2003) 'The European Union: Towards a Strategic Culture?', Security Dialogue, 34(4), 479-496.

Smith, Michael E. (2011) 'A liberal grand strategy in a realist world? Power, purpose and the EU's changing global role', Journal of European Public Policy 18(2), 144-63.

Wagnsson, Charlotte (2008) EU: Strategic Actor, Pragmatic Re-actor or Passive Pole? In Kjell Engelbrekt and Jan Hallenberg (Eds.), The European Union and Strategy: An Emerging Actor, London: Routledge, 184-99.

Wedin, Lars (2008) The EU as a Military Strategic Actor, In Kjell Engelbrekt and Jan Hallenberg (Eds.), The European Union and Strategy: An Emerging Actor, London: Routledge, 40-55. 